\title{
LEFT VENTRICULAR FUNCTION AT REST AND DURING EXERCISE*
}

\author{
By CARLETON B. CHAPMAN, $\dagger$ ORLAND BAKER $\ddagger$ AND JERE H. MITCHELL
}

(From the Cardiopulmonary Laboratory, Department of Internal Medicine, The University of Texas

Southwestern Medical School, Dallas, Texas)

(Submitted for publication December 29, 1958; accepted February 24, 1959)

The principle that the degree of ventricular filling at the end of diastole is a determinant of the work done during the succeeding contraction (in the isolated frog heart) stems from Frank (1). Further clarification was achieved by Rohde (2) who noted that ". . . the warm blooded heart is constructed in so complex a manner . . . that it seems hopeless to search for relations between heart volume and length of single muscle fibers. ....We must [therefore] rearrange the Frank formula ... so that we can use volume instead of fiber length." Straub (3) was no less explicit when he wrote: "As a specific indication of the length of the muscle elements the volume curve is used as suggested by Frank, and for the representation of tension the pressure curve is used."

Patterson, Piper and Starling (4), acknowledging all the above contributions, concluded that "the increased energy of the heart's contraction under conditions of increased pressure or increased inflow must be ascribed to alterations in the length of the muscle fibres at the beginning of and during their state of excitation, and not to changes in the tension on the fibres." They supported their conclusions relative to isolated canine and tortoise hearts by using a cardiometer for measuring change in ventricular volume and, in effect, used volume as an index to fiber length. The British workers were, therefore, basically in agreement with their German predecessors and colleagues. All seem to have agreed, in addition, that ventricular diastolic pressure was an unreliable guide to ventricular diastolic volume and that the latter, not the former, should be used in the study of intrinsic myocardial responses to stress.

The lack of a method for following changes in ventricular volume in the intact animal or in

\footnotetext{
* Supported by grants from the United States Public Health Service (H-3701) and the Dallas Heart Association.

$\dagger$ Professor of Medicine, University of Texas Southwestern Medical School.

$\ddagger$ USPHS Postdoctoral Research Fellows.
}

man made it impossible to test satisfactorily the general applicability of the Frank-Starling principle. Starling, however, thought it might explain the response of the mammalian heart to physical exercise. In his Linacre Lecture (5) he says: "As a result [of exercise] the heart is over filled during diastole, and is impeded from emptying itself in systole: Its volume both in systole and diastole enlarges progressively until by the lengthening of the muscle fibres so much more active surfaces are brought into play within the fibres that the energy of the contraction becomes sufficient to drive on into the aorta during each systole the largely increased volume of blood entering the heart from the veins during the diastole." This logical extension to intact animals of a physiological fact established only for isolated heart preparations was, however, dubious even at the time it was written. Orthodiagraphic and other radiographic techniques, applied to human subjects at rest and during exercise, had in some instances already indicated that total cardiac volume probably decreased as a result of exercise (6-10). Also of more than passing interest in connection with the FrankStarling principle was von Anrep's finding (11) that adrenalin causes the canine heart to contract more forcibly with no prior increase, or even a decrease, in end-diastolic volume. Such results suggested that the Frank-Starling concept might require modification, if not outright rejection, insofar as the intact mammal is concerned. von Anrep's study certainly raised the possibility that the following concept, as defined by Patterson, Piper and Starling (4), might be an oversimplification: "The output of the heart is a function of its filling, the energy of its contraction depends on the state of dilatation of the heart's cavities."

Subsequently Nylin (12), using more refined roentgenologic methods than had previously been available, showed that cardiac size is maximal when the normal human subject is at rest and 
recumbent; changing from the recumbent to the standing position caused marked reduction in cardiac size. Still later, Liljestrand, Lysholm and Nylin (13) showed that at no time during exercise at increasing loads on a bicycle ergometer did heart size reach the maximum found by Nylin in comparable normal recumbent subjects. They did note, however, that as workloads increased so did cardiac size; but the augmentation of cardiac volume was never as much as would be expected in view of the associated increase in cardiac output per minute. These findings have recently been marshalled by Hamilton (14) as evidence against the general applicability of the Frank-Starling principle.

To this point, all available studies on intact human subjects utilized roentgenologic methods of questionable validity to determine total cardiac volume. None attempted or claimed to determine ventricular volume. The development by Rushmer of techniques for using certain left ventricular diameters in intact, unanesthetized dogs as indexes to volume change (15) permitted a more precise scrutiny of left ventricular response to exercise. $\mathrm{He}$ found that exercise usually caused a decrease in both systolic and diastolic left ventricular diameters and was of the opinion that the phenomenon was independent of rate changes within the physiologic range.

It has not been possible, to the present time, to follow change in the internal volume of the left ventricle at rest or during exercise in the intact animal or human being. For this reason, a biplane version of a uniplane cinefluorographic technique employed earlier by Rushmer and Thal (16) was adapted for estimation of left ventricular volume. The following study was designed for the purpose of examining the relation between left ventricular end-diastolic volume and stroke work of the succeeding contractions in the intact dog at rest and during exercise.

\section{METHOD}

A. Determination of left ventricular volume. The details of the method have been published elsewhere (17). In brief, a biplane cinefluorographic unit of the type devised by Ramsey and co-workers (18) was used to record left and right anterior oblique images of the canine heart at 30 frames per second during the transcardiac passage of radiopaque material. Ventricular images were then projected, using a still projector and the original $35 \mathrm{~mm}$. films, so that the sizes of the images corresponded exactly to that of the actual chamber. Tracings of each pair of images were made, questionable boundaries and valve planes being checked by constant reference to $16 \mathrm{~mm}$. reduction prints of the original $35 \mathrm{~mm}$. films as viewed with a special motion analysis projector. Two methods of calculation were used : One involved inserting the products of the planimetrically determined areas of corresponding left ventricular images into a regression equation developed from studies of casts and models of left ventricular cavities ${ }^{1}$; the other required measurement of corresponding diameters of the two ventricular images at $1 \mathrm{~mm}$. intervals from top to bottom. On the assumption that the left ventricular cavity is elliptical or circular in cross-section, the diameters were then used to calculate the volume of each $1 \mathrm{~mm}$. section of the ventricular cavity:

where

$$
\mathrm{V}=\pi \mathrm{h}\left(\frac{\mathrm{D}_{1}}{2} \times \frac{\mathrm{D}_{2}}{2}\right)
$$

$$
\begin{aligned}
\mathrm{V}= & \text { volume in ml., } \\
\mathrm{h}= & 1.0 \mathrm{~mm} ., \\
\mathrm{D}_{1}= & \text { ventricular diameter from left anterior oblique } \\
& \text { view and } \\
\mathrm{D}_{2}= & \text { corresponding diameter from right anterior oblique } \\
& \text { view. }
\end{aligned}
$$

Total ventricular volume was taken as the sum of the sectional volumes. The volume calculations in the present study were done by use of area products and the regression equation.

Since no independent means of measuring ventricular volume in the living intact animal has been devised, resort was made to elaborate model experiments for validation of the technique. These tests are also presented in detail in the previous description (17). An average error of less than 10 per cent seems likely although the tests, in some respects, are overly severe. Other tests show that under average conditions the technique always stops motion up to $80 \mathrm{~cm}$. per sec.; under optimal conditions, blurring is not encountered until a speed of $110 \mathrm{~cm}$. per sec. is reached.

B. Material and preparation. Six healthy mongrel dogs were employed. They were anesthetized with a mixture of chlorolose $(0.05 \mathrm{Gm}$. per $\mathrm{Kg}$.) and urethane $(0.5$ $\mathrm{Gm}$. per $\mathrm{Kg}$.) and tracheal cannulation or intubation was carried out as rapidly as possible. A No. 9 cardiac catheter with birdseye tip was then passed into the inferior vena cava just proximal to its junction with the atrium, or into the main pulmonary artery. No. 7 cardiac catheters were then inserted into the femoral or carotid artery and passed retrograde into the left ventricle or aorta (just distal to the aortic valve). In some instances pressures were recorded from both sites through a double lumen catheter. The natural frequency of the system employing a No. 7 catheter $(50 \mathrm{~cm}$. long) and a P23D transducer (Statham) is about 12 cps. A slight extension of usable range is obtained by use of mechanical damping. The best system available to us in the present work gives a virtually flat response to $20 \mathrm{cps}$. It was used to record left ventricular pressures in a few instances.

\footnotetext{
${ }^{1} \log \mathrm{y}=-0.3256+0.8062 \log \mathrm{x}$, where $\mathrm{x}=$ product of 2 ventricular areas and $y=$ ventricular volume.
} 
C. Procedure. The prepared dog was suspended horizontally, feet down, in front of the two fluoroscopic screens, using a special canvas body sling, so that both anterior oblique views of the heart could be recorded. The tracheal tube or cannula was then connected to a Douglas bag via a two-way valve. Arterial and ventricular catheters were connected to transducers which, in turn, were fed into a multichannel photographic electronic recorder. Exercise was administered with a galvanic stimulator the electrodes of which were attached to the upper portions of the hind limbs and to the pelvic region.

The injection catheter was then attached to a pneumatic injector loaded with 90 per cent Hypaque ${ }^{\circledR}$ solution (1.5 $\mathrm{ml}$. per $\mathrm{Kg}$.). Injection of the radiopaque medium was timed, with relation to filming, so that optimal visualization of the left ventricle could be achieved.

Resting runs were done 10 to 15 minutes after the dog was suspended in position. Mild rhythmic exercise was then administered for about 10 minutes. The amount of exercise was such as to cause resting oxygen consumption to increase three to four times. In order to eliminate the effects of body motion on the cinefluorograms, exercise was usually stopped at the instant the cameras were activated. In no instance did filming begin more than two seconds after cessation of exercise.

The two cameras usually are perfectly synchronized. Under some circumstances, however, one camera leads the other by one-sixtieth of a second. When this happens, a warning circuit is activated so that the leading camera can be identified. Corrections are then introduced so that the ventricular images are made synchronous. The photographic pressure tracings bear markings indicating the precise instant at which one of the cameras records its image. In this way, the pressures corresponding to each ventricular volume figure can be identified.

D. Calculations. Ventricular volume and pressure curves are first plotted together (Figures 1 and 2, Tables I and II). Ejection curves are then plotted separately and, if necessary, smooth curves are drawn, in lieu of directly connecting the actual points (Figures 3 and 4). From these, the volume in ml. ejected for each one-thirtieth of a second ( $\Delta V$ in Tables $I$ and II) can be read off. Aortic cross-sectional area is calculated for each ejection increment by measuring aortic diameters $2 \mathrm{~cm}$. above the aortic valve and applying the equation for the area of a circle or an ellipse. Adjacent values for aortic cross-sectional area are averaged and mean velocity for the interval between each two points on the ejection curve is then calculated. Plots of ejection velocity are thus made possible (Figures 3 and 4). A somewhat similar method utilizing an aortic distensibility curve (and thus taking change in aortic cross-sectional area with pressure into account) was used to construct aortic velocity curves by Remington and Hamilton (19).

Pressure work $\left(W_{p}\right)^{2}$ for each stroke is first calculated from the conventional work equation:

where

$$
\mathrm{W}_{\mathrm{p}}=\mathrm{PV} \text {, }
$$

$P=$ mean ejection pressure in $\mathrm{Gm}$. per $\mathrm{cm} .^{2}$ and

$\mathrm{V}=$ total stroke volume in $\mathrm{ml}$.

By plotting left ventricular pressure at each one-thirtieth

2 The terms pressure work, potential energy and pressurevolume work are by common usage synonymous insofar as the work of the heart is concerned.

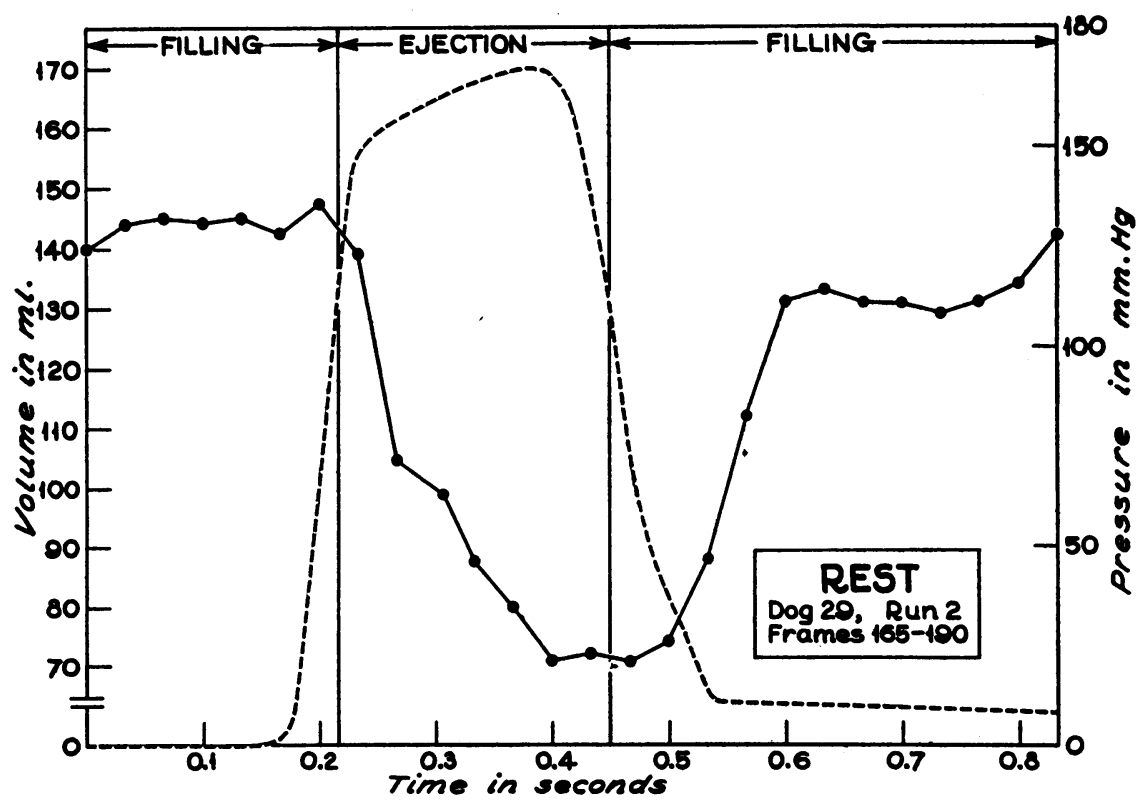

Fig. 1. Pressure-Volume Curves Through a Cardiac Cycle in the Anesthetized Resting Dog

The solid line refers to volume; the broken line to pressure (see Table I). 


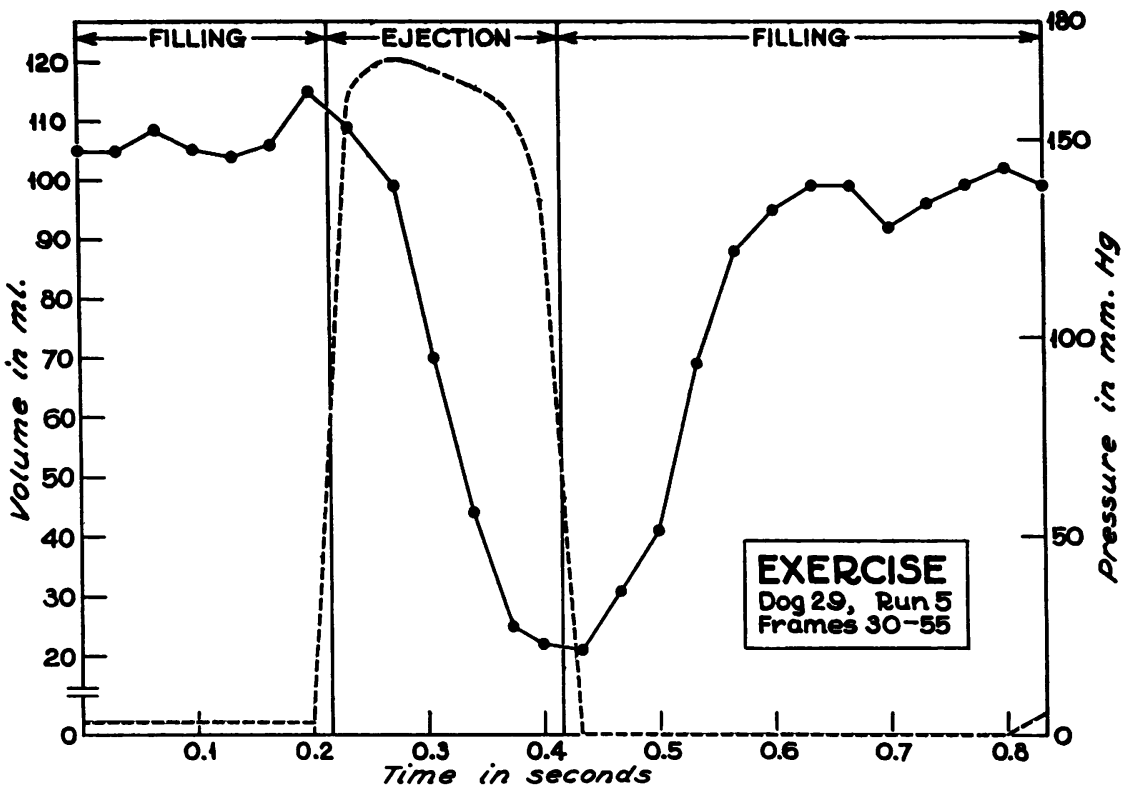

Fig. 2. Pressure-Volume Curves Through a Cardiac Cycle in the ANESTHETIZED EXERCising DoG

The solid line refers to volume; the broken line to pressure (see Table II).

of a second interval against the corresponding left ventricular volume, one obtains a pressure-volume work loop (Figure 5). The area under the ejection portion of the loop (connected to the zero pressure line by dropping perpendiculars) corresponds to integrated pressure work per stroke:

$$
\mathrm{W}_{\mathrm{p}}=\int_{t_{0}}^{t_{1}} \mathrm{PdV}
$$

TABLE I

Values obtained during one cycle in a normal resting anesthetized dog *

\begin{tabular}{|c|c|c|c|c|c|c|}
\hline $\begin{array}{l}\text { Frame } \\
\text { number }\end{array}$ & $\underset{(m m . H g)}{\text { L.V. }}$ & $\underset{(m l .)}{\text { volume }}$ & $\underset{(m l .)}{\Delta \mathrm{V}}$ & $\begin{array}{c}\text { Aortic } \\
\text { X-sect. } \\
\text { area } \\
\left(\mathrm{cm} .{ }^{2}\right)\end{array}$ & $\begin{array}{c}\mathbf{v} \\
\text { (velocity) } \\
(\mathrm{cm} . / \mathrm{sec} .)\end{array}$ & $\begin{array}{c}\Delta \text { Power } \\
(\mathrm{Gm} . \mathrm{cm} . / \mathrm{sec} .)\end{array}$ \\
\hline $\begin{array}{l}165 \\
166 \\
167 \\
168 \\
169 \\
170 \\
171 \\
172 \\
173 \\
174 \\
176 \\
177 \\
178 \\
179 \\
180 \\
181 \\
182 \\
183 \\
184 \\
185 \\
186 \\
187 \\
188 \\
189 \\
190\end{array}$ & $\begin{array}{r}0 \\
0 \\
0 \\
0 \\
0 \\
0 \\
106 \\
150 \\
157 \\
163 \\
169 \\
169 \\
134 \\
65 \\
39 \\
11 \\
11 \\
11 \\
11 \\
11 \\
11 \\
8 \\
8 \\
8 \\
8\end{array}$ & $\begin{array}{r}140 \\
144 \\
145 \\
144 \\
145 \\
141 \\
148 \\
139 \\
105 \\
99 \\
80 \\
71 \\
72 \\
71 \\
74 \\
88 \\
112 \\
131 \\
133 \\
131 \\
131 \\
129 \\
131 \\
134 \\
142\end{array}$ & $\begin{array}{r}-1.0 \\
-1.0 \\
-1.5 \\
-1.0 \\
-1.0 \\
-1.0 \\
9.0 \\
22.5 \\
17.0 \\
10.5 \\
5.8 \\
2.8 \\
0.8 \\
-4.0 \\
-14.0 \\
-23.5 \\
-19.3 \\
-1.7 \\
0 \\
0.5 \\
-0.5 \\
-0.5 \\
-0.5 \\
-\quad 1.0\end{array}$ & $\begin{array}{l}2.8 \\
3.1 \\
3.2 \\
3.2 \\
4.1 \\
4.1 \\
3.8\end{array}$ & $\begin{array}{r}95 \\
218 \\
161 \\
100 \\
42 \\
20 \\
6\end{array}$ & $\begin{array}{r}-11,000 \\
48,000 \\
142,000 \\
118,000 \\
72,000 \\
40,000 \\
17,000 \\
3,000 \\
-8,000 \\
-14,000 \\
-10,000 \\
-8,000 \\
-1,000\end{array}$ \\
\hline
\end{tabular}

* These data are the basis on which Figures 1, 3, 4, 5 and 6 are constructed. 
TABLE II

Values during one cycle in a normal exercising anesthetized dog*

\begin{tabular}{|c|c|c|c|c|c|c|}
\hline $\begin{array}{c}\text { Frame } \\
\text { number }\end{array}$ & 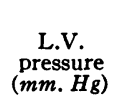 & 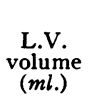 & $\underset{(m l .)}{\Delta \mathrm{V}}$ & $\begin{array}{c}\text { Aortic } \\
\text { X-sect. } \\
\text { area } \\
\left(\mathrm{cm} .{ }^{2}\right)\end{array}$ & $\begin{array}{c}\mathbf{v} \\
\left(\begin{array}{c}\text { velocity) } \\
(\mathrm{cm} . / \mathrm{sec} .)\end{array}\right.\end{array}$ & $\begin{array}{c}\Delta \text { Power } \\
(\mathrm{Gm} . \mathrm{cm} . / \mathrm{sec} .)\end{array}$ \\
\hline $\begin{array}{l}30 \\
31 \\
32 \\
33 \\
34 \\
35 \\
36 \\
37 \\
38 \\
39 \\
40 \\
41 \\
42 \\
43 \\
44 \\
45 \\
46 \\
47 \\
48 \\
49 \\
50 \\
51 \\
52 \\
53 \\
54 \\
55\end{array}$ & $\begin{array}{r}3 \\
3 \\
3 \\
3 \\
3 \\
3 \\
22 \\
161 \\
171 \\
168 \\
164 \\
158 \\
135 \\
0 \\
0 \\
0 \\
0 \\
0 \\
0 \\
0 \\
0 \\
0 \\
0 \\
0 \\
0 \\
6\end{array}$ & $\begin{array}{r}105 \\
105 \\
107 \\
105 \\
104 \\
106 \\
115 \\
109 \\
99 \\
70 \\
44 \\
25 \\
22 \\
21 \\
31 \\
41 \\
69 \\
88 \\
95 \\
99 \\
99 \\
92 \\
96 \\
99 \\
102 \\
99\end{array}$ & $\begin{array}{r}-4.0 \\
-\quad 3.0 \\
-2.0 \\
-\quad 2.0 \\
-\quad 3.0 \\
-4.0 \\
5.5 \\
10.0 \\
26.5 \\
32.0 \\
16.0 \\
2.5 \\
1.2 \\
-6.0 \\
-13.0 \\
-29.0 \\
-21.0 \\
-3.0 \\
-1.5 \\
-1.5 \\
-1.0 \\
-1.0 \\
-1.0 \\
-1.0 \\
-1.0\end{array}$ & $\begin{array}{l}2.3 \\
2.6 \\
3.2 \\
3.5 \\
3.9 \\
3.8 \\
3.6\end{array}$ & $\begin{array}{r}72 \\
116 \\
249 \\
272 \\
123 \\
20 \\
10\end{array}$ & $\begin{array}{r}-2,000 \\
16,000 \\
52,000 \\
161,000 \\
198,000 \\
81,000 \\
11,000 \\
2,000\end{array}$ \\
\hline
\end{tabular}

* These data are plotted in Figures 2, 3, 4, 5 and 6.

In actual practice, volume in $\mathrm{ml}$. is plotted on the abscissa and pressure (in $\mathrm{mm} . \mathrm{Hg}$ ) is plotted on the ordinate. The area under the ejection portion of the loop is measured

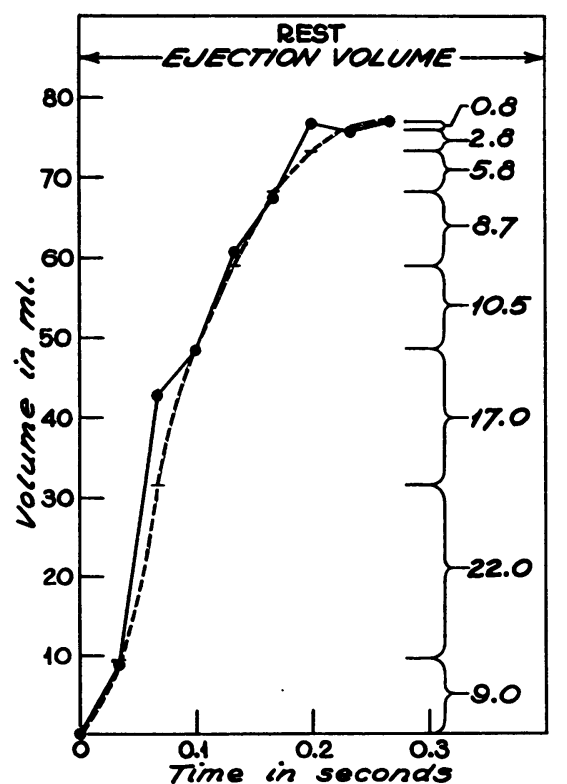

planimetrically and correcting factors are applied to reduce the area to fundamental terms. The factor 1.355 is introduced in order to convert $\mathrm{mm}$. $\mathrm{Hg}$ to $\mathrm{Gm}$. per $\mathrm{cm} .{ }^{2}$. The

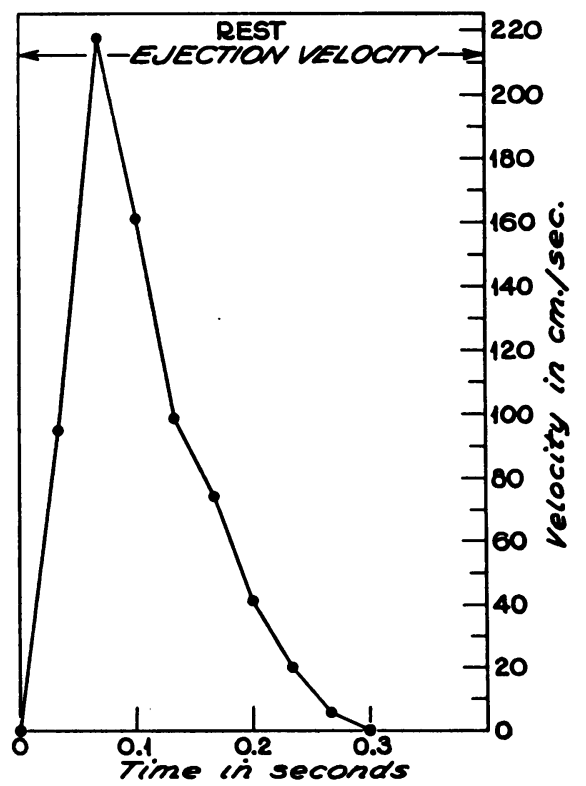

Fig. 3. Resting Ejection Curve (Left) and Velocity Curve (Right)

The observed ejection curve is represented by the solid line. The broken line represents the curve, fitted free hand to the available data, from which velocity was calculated (see Table I). 


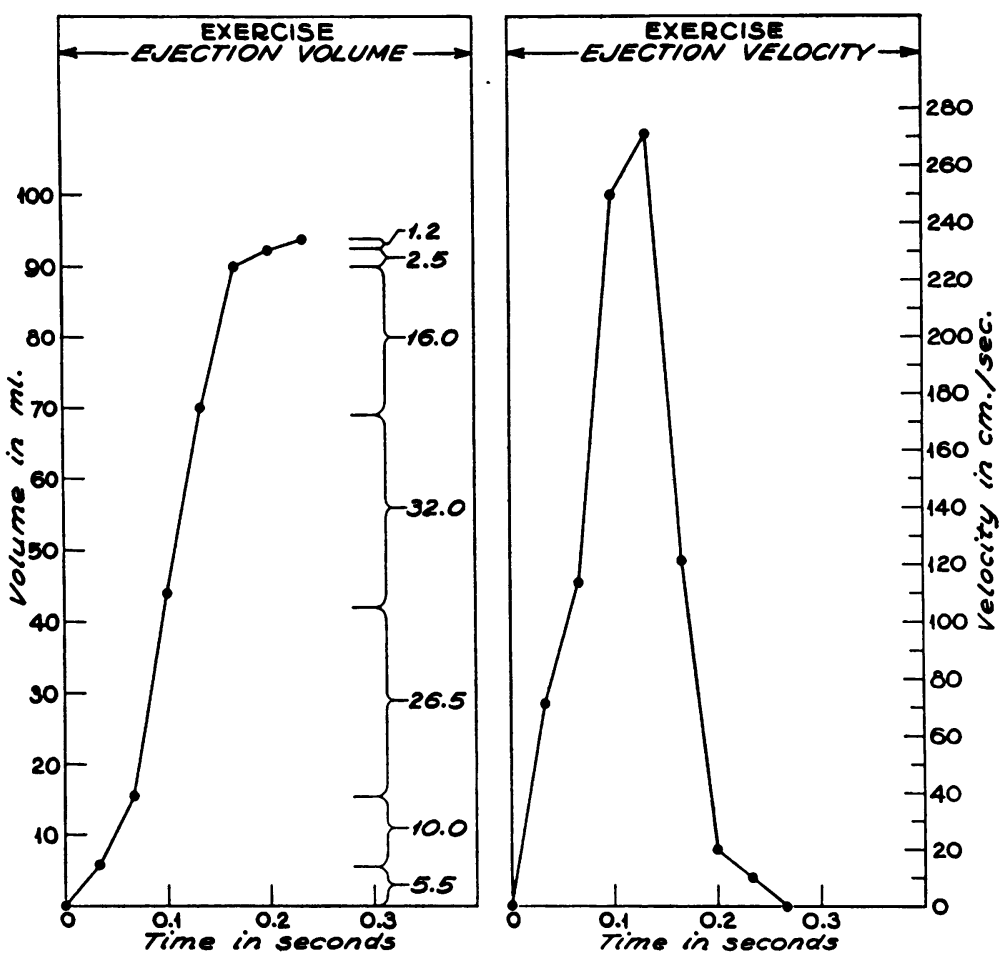

Fig. 4. Exercising Ejection (Left) and Velocity (Right) Curves See Table II.

final value is in $\mathrm{Gm} . \mathrm{cm}$. units $\left(\mathrm{Gm}\right.$. per $\mathrm{cm}^{2} \times \mathrm{cm}^{3}=$ $\mathrm{Gm}$. cm.). For example, $W_{p}$ was calculated from the resting loop in Figure 5 by plotting volume on the abscissa so that $10 \mathrm{ml}$. $=1.0 \mathrm{~cm}$. paper, and pressure on the ordinate so that $10 \mathrm{~mm}$. $=1.0 \mathrm{~cm}$. paper. The area under the ejection portion of the loop was $119.68 \mathrm{~cm} .^{2}$. This, multiplied by $135.5(1.355 \times 100)$, gives $16,217 \mathrm{Gm}$. cm. The data on which the loop is based are given in Table I.

Kinetic work $\left(W_{k}\right)^{3}$ per stroke may also be calculated from mean values:

where

$$
W_{k}=\frac{m v^{2}}{2 g}
$$

$\mathrm{m}=$ total stroke mass in $\mathrm{Gm}$. (total stroke volume in $\mathrm{ml} . \times 1.06$ )

$\mathbf{v}=$ mean stroke velocity in $\mathrm{cm}$. per sec. and

$\mathrm{g}=980 \mathrm{~cm}$. per sec. ${ }^{2}$.

In order to obtain the value

$$
W_{k}=\int_{t_{0}}^{t_{1}} \frac{v^{2} d m}{2 g},
$$

$\mathrm{v}^{2}$ for each one-thirtieth of a second interval must be plotted against mass ejected during the same interval. The area under the resulting curve, when appropriately converted to absolute units, yields integrated kinetic work in $\mathrm{Gm} . \mathrm{cm}$. For example, $W_{k}$ for the cycle shown in

${ }^{3}$ Also known as kinetic energy, acceleration work or energy of velocity.
Figure 6 is obtained by plotting $v^{2}$ (Table I) against mass ejected for each one-thirtieth of a second during ejection. Mass, on the abscissa, is plotted so that $10 \mathrm{Gm} .=1 \mathrm{~cm}$. Velocity squared, on the ordinate, is plotted so that 5,000 $\mathrm{cm} .{ }^{2}$ per sec. ${ }^{2}=1 \mathrm{~cm}$. The area under the curve is 34.0 $\mathrm{cm}^{2}{ }^{2}$. This value is multiplied by $5,000 \times 10 / 1,960$, or 25.51 , to yield $W_{k}$ in $\mathrm{Gm}$. cm. In this case, the answer is $867.3 \mathrm{Gm} . \mathrm{cm}$.

Total stroke work is, of course, the sum of $\mathrm{W}_{\mathrm{p}}$ and $\mathrm{W}_{\mathrm{k}}$, whether calculated from mean or integrated values.

$A$ power curve representing the rate at which work is done during the cardiac cycle is obtained if total work $\left(W_{p}+W_{k}\right)$ done on blood in each one-thirtieth of a second interval during ejection is plotted against elapsed time from the beginning of ejection. The course of power development and the relation between pressure and kinetic power at rest and during exercise are shown in Figure 7. Power may also be obtained as the first derivative of the cumulative work curve. The fundamental difference between work and power is made apparent by comparing Figures 6 (work) and 7 (power).

E. Possible sources of error. The error inherent in the method itself, as defined previously (17), is small enough to be acceptable for present purposes. The most serious remaining objection to the technique is the cardiovascular effect of highly concentrated contrast medium, delivered very rapidly into the vena cava or pulmonary artery. It has been shown by Muirhead, Lackey, Bunde and Hill (20) that rapid injection of highly concentrated solutions into the heart of ten produces bradycardia, an effect which 

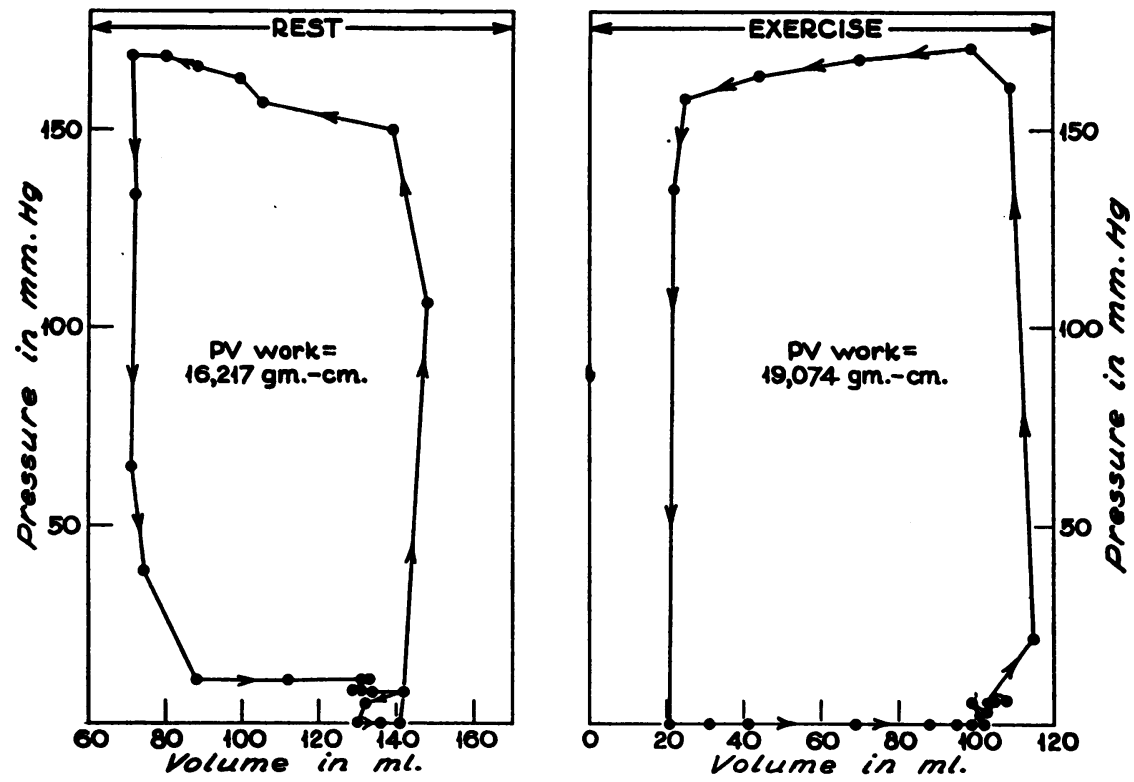

Fig. 5. Pressure-Volume Work Loops, Resting and Exercising

The data on which the loops are based are set out in Tables I (resting) and II (exercising). The area under the ejection portion of the resting loop corresponds to the value

$$
\int_{V-75}^{v=145} \operatorname{PdV}
$$

on the right, the corresponding value is

$$
\int_{\mathrm{V}-20}^{\mathrm{V}-110} \mathrm{PdV} \text {. }
$$

is abolished by vagotomy, as shown by Deyrup and Walcott (21). Some degree of arterial hypotension has also been observed following such injections. Both effects were frequently seen in the present studies. Bradycardia occurred most frequently when injection was into the pulmonary artery and sometimes abolished the usual increase in pulse rate produced by exercise. It occurred almost immediately after contrast medium reached the pulmonary
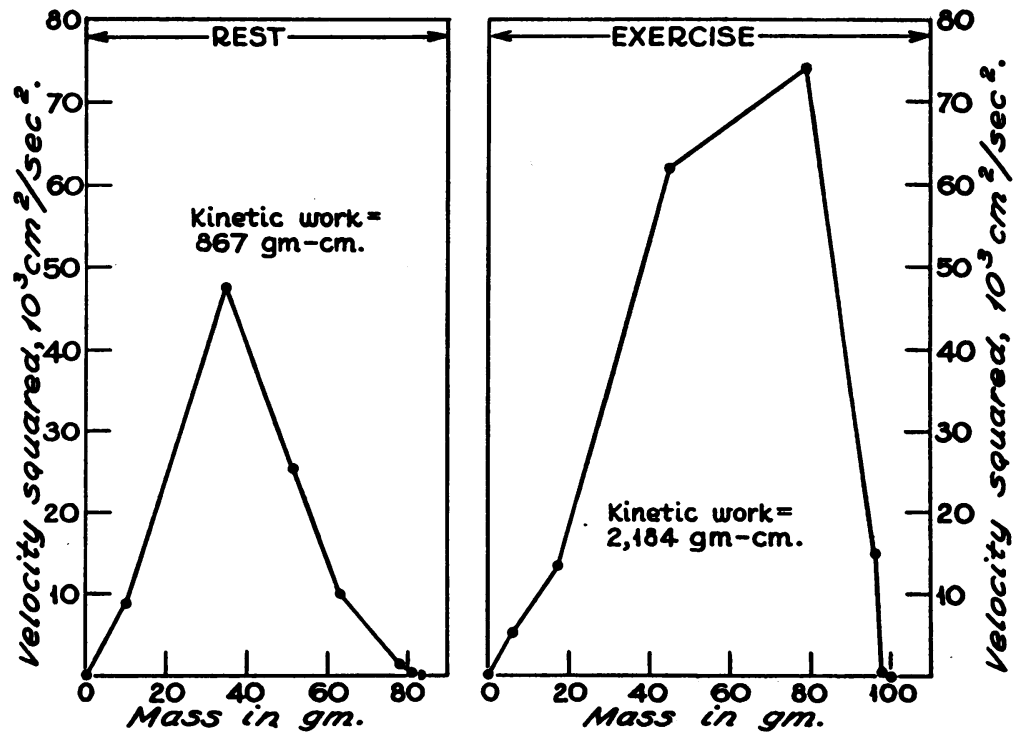

Fig. 6. Kinetic Work Curves at Rest and During Exercise

See Tables I and II for data used to construct the curves. 
artery. Fall in arterial blood pressure, however, was invariably delayed and, as a rule, several measurable cycles had taken place before the effect became noticeable. There is reason to believe that the hypotensive effect is attributable, as suggested by Muirhead, Lackey, Bunde and Hill, to decline in left ventricular stroke volume, itself dependent on the arrival at the coronary capillaries of a sizable concentration of the contrast medium. The effect does not vitiate the present results, however, since cycles taking place after the beginning of the fall in arterial blood pressure were deleted. Enough unaffected cycles remained (three to 10) to permit adequate comparisons between resting and exercising conditions in the same dog. The bradycardic effect could not be eliminated but was marked in only two dogs. In actual fact, the effect fortuitously provided evidence that the effect of exercise on left ventricular function is not wholly dependent on increase in pulse rate. The volume of contrast medium, delivered relatively suddenly into some portion of the central cardiovascular system, must also be taken into account. Whatever the effect of this factor on left ventricular function, it was common to both resting and exercising states. It is also probable that the increase in volume return to the left ventricle was not as sudden as might be surmised from the total volumes of contrast medium injected; since injection required 1.5 to 2.0 seconds, the increased return to the left ventricle was spread over several cycles.

\section{RESULTS}

Table III shows pulse rates and mean values for left ventricular end-diastolic, stroke and minute volumes at rest and during exercise. The pulse rates are those that obtained as the actual cycles that were used for volume calculations took place.

Stroke work and minute work, calculated by both methods (using mean values, on the one hand, and the integration procedure, on the other), are shown in Table IV. The pulse rates
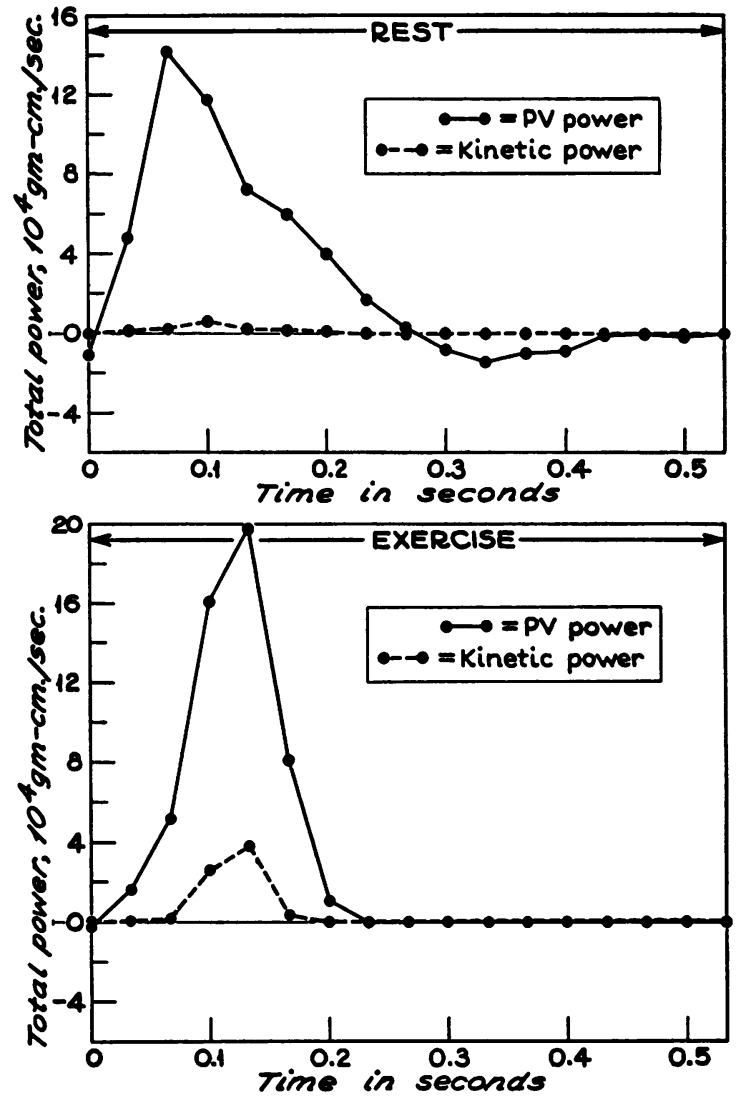

Fig. 7. Power Curves at Rest and During Exercise

given in Table III were used to convert stroke to minute work.

A sample plot of total stroke work at rest against end-diastolic volume is set out in Figure 8. A similar plot, showing both resting and exercising values in a normal dog, without left ventricular failure, is seen in Figure 9. Identical

TABLE III

Left ventricular end-diastolic, stroke and minute volume for entire normal group*

\begin{tabular}{|c|c|c|c|c|c|c|c|c|c|}
\hline \multirow{2}{*}{$\begin{array}{c}\text { Dog } \\
\text { number }\end{array}$} & \multirow{2}{*}{$\begin{array}{l}\text { Wt. } \\
(\boldsymbol{K g} .)\end{array}$} & \multicolumn{2}{|c|}{$\begin{array}{l}\text { End-diastolic volume } \\
(\mathrm{ml} .)\end{array}$} & \multicolumn{2}{|c|}{$\begin{array}{c}\text { Stroke volume } \\
(m l .)\end{array}$} & \multicolumn{2}{|c|}{ Pulse rate } & \multicolumn{2}{|c|}{$\underset{(L . / \text { min. })}{\text { Minute volume }}$} \\
\hline & & Rest & Exercise & Rest & Exercise & Rest & Exercise & Rest & Exercise \\
\hline $\begin{array}{l}13 \\
14 \\
15 \\
26 \\
29 \\
30\end{array}$ & $\begin{array}{l}15.8 \\
17.3 \\
17.3 \\
22.3 \\
24.6 \\
20.2\end{array}$ & $\begin{array}{r}80 \pm 2.8 \\
66 \pm 9.1 \\
83 \pm 5.4 \\
126 \pm 14.0 \\
138 \pm 5.2 \\
126 \pm 4.2\end{array}$ & $\begin{array}{r}68 \pm 5.0 \\
56 \pm 14.8 \\
71 \pm 6.5 \\
107 \pm 6.8 \\
107 \pm 4.4 \\
96 \pm 6.2\end{array}$ & $\begin{array}{l}28 \pm 2.7 \\
29 \pm 10.8 \\
27 \pm 4.6 \\
77 \pm 13.0 \\
84 \pm 4.7 \\
71 \pm 9.7\end{array}$ & $\begin{array}{l}34 \pm 6.6 \\
28 \pm 1.8 \\
33 \pm 7.2 \\
73 \pm 8.3 \\
83 \pm \\
72 \pm 7.4\end{array}$ & $\begin{array}{r}125 \\
136 \\
160 \\
90 \\
66 \\
55\end{array}$ & $\begin{array}{r}160 \\
210 \\
160 \\
84 \\
82 \\
99\end{array}$ & $\begin{array}{l}3.2 \pm 0.3 \\
3.9 \pm 1.4 \\
4.0 \pm 0.7 \\
6.9 \pm 1.6 \\
5.0 \pm 1.2 \\
4.2 \pm 1.3\end{array}$ & $\begin{array}{l}5.1 \pm 0.9 \\
5.6 \pm 0.3 \\
5.1 \pm 1.1 \\
5.4 \pm 1.0 \\
6.2 \pm 0.9 \\
6.9 \pm 0.9\end{array}$ \\
\hline $\begin{array}{l}\text { Mean } \\
\mathbf{n} \\
\sigma_{\mathbf{D}}\end{array}$ & & $100 \frac{ \pm}{37} 28.2$ & ${ }_{8}^{89} \frac{ \pm}{32} 19.9$ & $49 \pm \frac{26.4}{37}$ & $\begin{array}{l}59 \pm 22.4 \\
.9\end{array}$ & & & $\begin{array}{r}4.6 \pm 1.7 \\
\quad 0 .\end{array}$ & ${ }_{35}^{5.9} \frac{1}{32} 1.2$ \\
\hline
\end{tabular}

* The $\mathrm{n}$ refers to total cycles used to derive the mean values. 


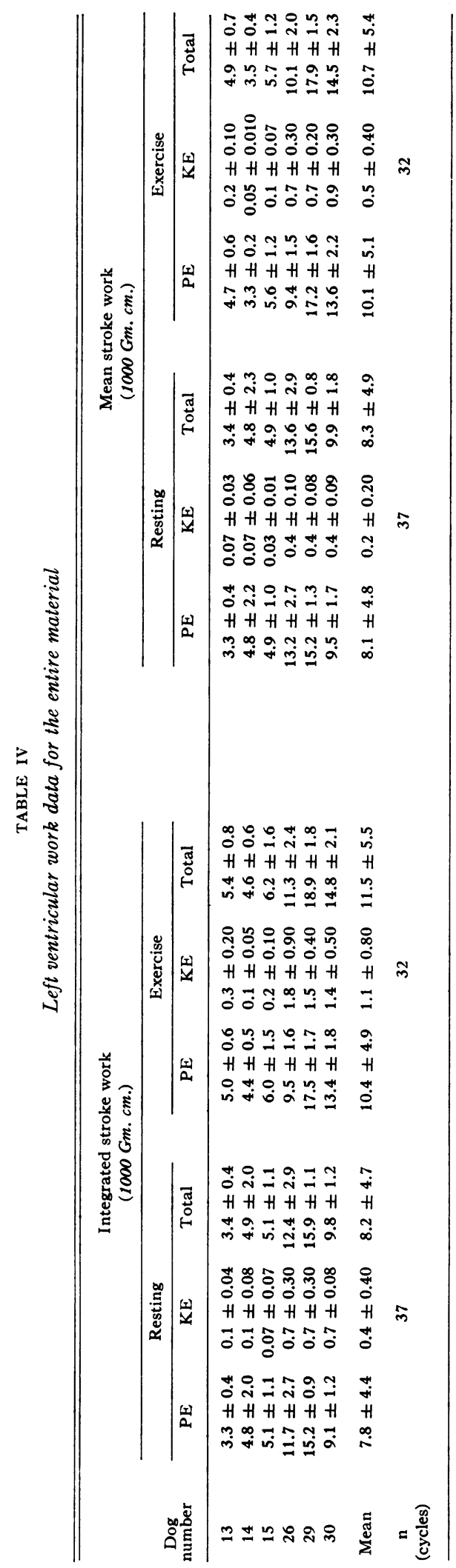




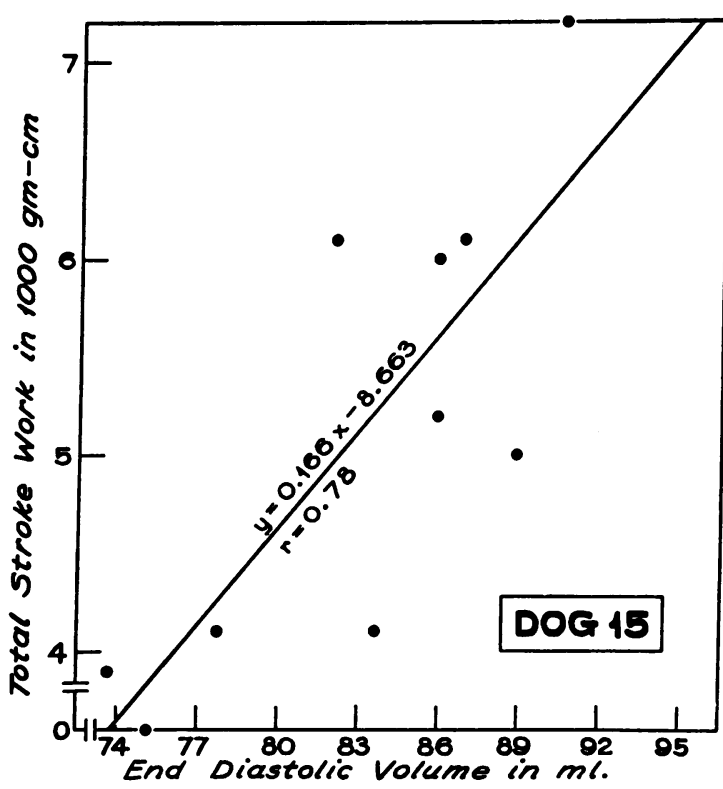

Fig. 8. Relation Between Left Ventricular EndDiastolic Volume and Stroke Work During $10 \mathrm{Con}$ secutive Cycles in a Resting, Anesthetized Dog with No Evidence of Left Ventricular FaILURe

qualitative relations prevailed in five other dogs. Attempts to relate left ventricular end-diastolic pressure and stroke work, at rest or during exercise, were unsuccessful. In Dog 15, for example, end-diastolic pressure was zero for 10 successive resting cycles, yet stroke work varied from 3.6 to 7.2 thousand $\mathrm{Gm}$. cm. Owing, however, to the fact that variations in intrapleural pressures were not measured, the figures shown are not effective pressures. It is therefore not possible to use the data to establish or deny a direct relation in the intact animal between enddiastolic pressure and work done in the succeeding contraction.

\section{DISCUSSION}

The data presented confirm the basic FrankStarling hypothesis for the intact resting dog: A definite relation exists, between left ventricular end-diastolic volume and the work of the stroke immediately following, provided conditions are held reasonably constant while the observation is being made. The plot shown in Figure 8 is representative of the relationship as disclosed by the method in resting, intact, anesthetized dogs. Spontaneously occurring changes in ventricular function under these conditions provide a suffi- cient range of end-diastolic volume and stroke work to show that a linear or gently curvilinear relation exists between the two variables.

The effect of mild exercise in the nonfailing, intact, anesthetized dog is well shown in Figure 9 and Table III. The pattern in Figure 9 was seen in six animals; in each, the resting values fall to the right and are quite low (with reference to the ordinate), while the exercising values are to the left (lower end-diastolic volume) and higher (in terms of stroke work). In other words, exercise usually produces a decrease in both end-diastolic and end-systolic left ventricular volume; stroke work and usually stroke volume are, at the same time, increased. In general, the findings are in keeping with the older orthodiagraphic studies and closely parallel the results of Rushmer's elegant experiments (15), using left ventricular diameters as indexes to volume.

It seems clear, therefore, that the basic Starling relation prevails under resting conditions

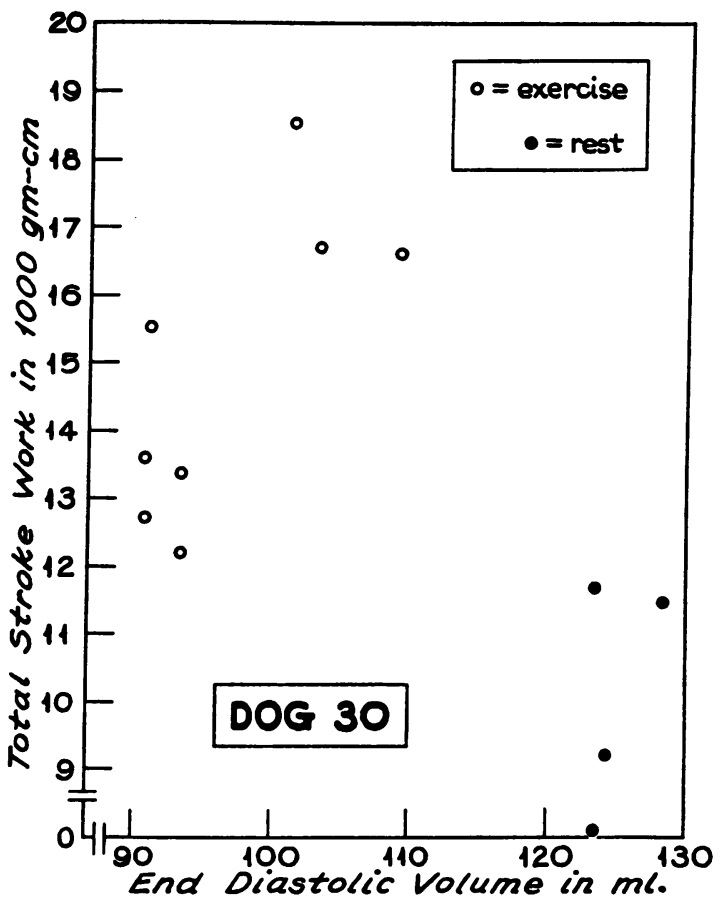

Fig. 9. Plots of Resting Values for the NonfaIling Left Ventricle (END-Diastolic Volume Versus Stroke Work) Compared to a Plot of Exercising VALUES

Note the decline in end-diastolic volume (abscissa) and increase in stroke work (ordinate) occasioned by exercise. 
and that it may also be operative during mild exercise. But the fact that end-diastolic volume during exercise is normally less than at rest, at a time when stroke work is actually increased, indicates that exercise imposes some basic functional difference on the nonfailing ventricle. The data reported may conceivably represent segments of ventricular function curves, the exercise curve lying above and to the left of the resting. If this is true, the results are in keeping with Sarnoff and Berglund's ingenious concept $(22,23)$ of a "family of curves," each one representing a different set of conditions under which the ventricle is operating. The results do not actually define a curve of any sort but clearly show that the ventricle is operating at different functional levels, as defined by the relation between end-diastolic volume and stroke work, at rest and during exercise. The data fit equally well on the set of curves as drawn by Hamilton (14) but provide no information concerning a descending limb.

The ultimate role of the basic Frank-Starling principle in ventricular function remains to be fully defined but it cannot be dismissed as a phenomenon observable only in the heart-lung or open chest preparation. Insofar as the intact organism is concerned, it must be interdigitated with other known control mechanisms. It may be that the Frank-Starling feedback mechanism is the fundamental mechanism by which the ventricle responds to changing demands and that various neural or neurohumeral control systems operate primarily to shift the ventricular function curve, whatever its shape, upward or downward. With further refinements in techniques for measuring change in ventricular volume, remaining questions concerning the Frank-Starling mechanism should become approachable.

As a by-product of the study it was found that use of mean instead of integrated values for calculating stroke work regularly yielded values that were too small. At rest, however, the size of the underestimate was not serious. During exercise the error introduced by use of mean values becomes more consequential, especially when one considers the kinetic work category (Figure 7). The strong probability is that for any but resting conditions it is hazardous to follow the usual practice of calculating pressure work only (ignoring kinetic work altogether) and of using mean values (minute volume divided by pulse rate for stroke volume; systolic plus diastolic divided by 2 for mean pressure). Use of the work convention, borrowed from hydraulics, is probably not justified unless the correct items are actually measured and the data are integrated where necessary.

\section{CONCLUSIONS}

1. The basic Frank-Starling principle, relating end-diastolic volume and stroke work, is valid for the intact anesthetized dog.

2. End-diastolic and end-systolic volumes regularly decrease with the onset of mild exercise in the same preparation. Stroke work usually increases during exercise.

3. Pressure and kinetic work are usually underestimated when calculated from mean values for pressure, volume and velocity instead of from integrated data.

\section{REFERENCES}

1. Frank, O. Zur Dynamik des Herzmuskels. Z. Biol. 1895, 32, 370.

2. Rohde, E. Uber den Einfluss der mechanischen Bedingungen auf die Tätigkeit und den Sauerstoffverbrauch des Warmblüterherzens. NaunynSchmiedeberg's Arch. Exp. Path. Pharmak. 1912, 68, 401.

3. Straub, H. Dynamik des Säugertierherzens. Dtsch. Arch. klin. Med. 1914, 115, 531.

4. Patterson, S. W., Piper, H., and Starling, E. H. The regulation of the heart beat. J. Physiol. (Lond.) 1914, 48, 465.

5. Starling, E. H. Linacre Lecture on the Law of the Heart, given at Cambridge, 1915. New York, Longmans, Green and Co., 1918.

6. Raab, L. Zur Frage von der akuten Dilatation des Herzens durch Überanstrengung. Münch. med. Wschr. 1909, 56, 555.

7. Gordon, B. The effect of effort on the size of the heart. Observations on animals and marathon runners. Amer. J. Roentgenol. 1925, 14, 424.

8. Williamson, C. S. The effects of exercise on the normal and pathological heart; based upon the study of one hundred cases. Amer. J. med. Sci. 1915, 149, 492.

9. Dietlen, H., and Moritz, F. Uber das Verhalten des Herzens nach langdauerndem und anstrengendem Radfahren. Münch. med. Wschr. 1908, 55, 489.

10. Kienböck, R., Selig, A., and Beck, R. Untersuchungen an Schwimmern. Münch. med. Wschr. 1907, 54, 1427. 
11. von Anrep, G. On the part played by the suprarenals in the normal vascular reactions of the body. J. Physiol. (Lond.) 1912, 45, 307.

12. Nylin, G. Relation between heart volume and stroke volume in recumbent and erect positions. Skand. Arch. Physiol. 1934, 69, 237.

13. Liljestrand, G., Lysholm, E., and Nylin, G. The immediate effects of muscular work on the stroke and heart volume in man. Skand. Arch. Physiol. 1938, 80, 265.

14. Hamilton, W. F. Role of the Starling concept in regulation of the normal circulation. Physiol. Rev. 1955, 35, 161.

15. Rushmer, R. F. Continuous measurements of left ventricular dimensions in intact, unanesthetized dogs. Circulat. Res. 1954, 2, 14.

16. Rushmer, R. F., and Thal, N. Factors influencing stroke volume: A cinefluorographic study of angiocardiography. Amer. J. Physiol. 1952, 168, 509.

17. Chapman, C. B., Baker, O., Reynolds, J., and Bonte, F. J. Use of biplane cinefluorography for measurement of ventricular volume. Circulation 1958, 18, 1105.
18. Ramsey, G. H. S., Watson, J. S., Jr., Steinhausen, T. B., Thompson, J. J. Dreisinger, F., and Weinberg, S. Cinefluorography. Radiology 1949, 52, 684.

19. Remington, J. W., and Hamilton, W. F. The evaluation of the work of the heart. Amer. J. Physiol. 1947, 150, 292.

20. Muirhead, E. G., Lackey, R. W., Bunde, C. A., and Hill, J. M. Transient hypotension following rapid intravenous injections of hypertonic solutions. Amer. J. Physiol. 1947, 151, 516.

21. Deyrup, I. J., and Walcott, W. W. Mechanism of vagal cardiac slowing following intravenous injection of small volumes of strongly hypertonic solutions. Amer. J. Physiol. 1948, 154, 336.

22. Sarnoff, S. J. Myocardial contractility as described by ventricular function curves; observations on Starling's law of the heart. Physiol. Rev. 1955, $35,107$.

23. Sarnoff, S. J., and Berglund, E. Ventricular function. I. Starling's law of the heart studied by means of simultaneous right and left ventricular function curves in the dog. Circulation 1954, 9, 706. 